\title{
Optic Neuropathy and Sinus Disease
}

\author{
David Gallagher ${ }^{\mathrm{a}}$, Clare Quigley ${ }^{\mathrm{b}}$, Conor Lyons ${ }^{\mathrm{c}}$, \\ Elizabeth McElnea ${ }^{\mathrm{c}, \mathrm{d}}$, Tim Fulcher ${ }^{\mathrm{b}}$
}

\begin{abstract}
We describe two cases of optic neuropathy related to sinus disease. Sinusitis is an uncommon cause of the same. Nonetheless, it demands an accurate diagnosis with prompt, appropriate management which in some cases must be surgical. The cases described highlight the potential for much variability in outcome.
\end{abstract}

Keywords: Sinusitis; Optic neuropathy; Optic neuritis; Onodi cell; Sphenoethmoiditis

\section{Introduction}

Optic neuropathy refers to damage of the optic nerve. It may be associated with infectious, inflammatory, compressive, neoplastic, auto-immune or vascular processes [1]. The main symptom is loss of vision. Degeneration of optic nerve fibers may occur and lead to complete and permanent vision loss.

Optic neuritis is an inflammatory neuropathy of the optic nerve. Among the very wide variety of conditions that cause optic neuritis, demyelinating disease, in particular multiple sclerosis continues to be the most common and indeed has dominated study into this condition.

Optic neuritis and/or neuropathy secondary to sinus disease are infrequent but documented associations [2]. The relationship remains controversial however. There is scant available literature corroborating the connection with the result that some clinicians continue to discount completely the association [3].

Probably the best evidence for the relationship is orbital cellulitis wherein there is orbital inflammation which may be accompanied by signs of optic nerve dysfunction and radio-

Manuscript submitted September 27, 2017, accepted December 8, 2017

aDepartment of Ophthalmology, University Hospital Galway, University Road, Galway, Ireland

bepartment of Ophthalmology, Mater Misericordiae University Hospital, Eccles Street, Dublin, Ireland

'Department of Ophthalmology, Royal Victoria Eye and Ear Hospital, Adelaide Road, Dublin, Ireland

dCorresponding Author: Elizabeth McElnea, Department of Ophthalmology, Royal Victoria Eye and Ear Hospital, Adelaide Road, Dublin 4, Ireland.

Email: mcelneaelizabeth@gmail.com

doi: https://doi.org/10.14740/jmc2926w logical evidence of sinus infection [4].

Even with accurate diagnosis however, standardized medical and surgical treatment has not been defined and indications for sinus and/or optic nerve decompression have not been well elaborated [1].

\section{Case Reports}

\section{Case 1}

A 36-year-old Brazilian gentleman attended the eye casualty service with a 3-day history of worsening vision from his left eye. He had had headache for 1 week, worst at the vertex of his skull and worse on lying down. He also described pain over his left cheek and at the bridge of his nose.

He had taken nasal mometasone $200 \mu \mathrm{g}$ daily and amoxicillin $500 \mathrm{mg}$ orally three times daily for 3 days and subsequently levocetirizine $5 \mathrm{mg}$ orally nocte and azithromycin $500 \mathrm{mg}$ orally daily for 5 days for a "sinus infection" without symptomatic improvement.

At examination, this gentleman's Snellen visual acuity was $6 / 6$ from the right eye and 6/24 from his left eye. He had left relative afferent pupillary defect. His extraocular movements were not limited. Both optic nerve heads appeared normal.

Nasendoscopy revealed hyperemic mucosa and mucopurulent discharge at the inferior turbinate.

Laboratory investigations revealed white cell count (WCC) $11.3 \times 10^{9} / \mathrm{L}$ with neutrophils $7.2 \times 10^{9} / \mathrm{L}$, erythrocyte sedimentation rate (ESR) $65 \mathrm{~mm} / \mathrm{h}$ and C-reactive protein (CRP) $28 \mathrm{mg} / \mathrm{L}$. As can be seen from Figures 1 and 2, computed tomography (CT) showed opacification of the sphenoidal and ethmoidal sinuses on the left with communication between a posterior left ethmoid sinus and an accessory air cell within the left anterior clinoid process - an Onodi air cell which was similarly opacified. The latter was directly adjacent to the path of the left optic nerve. Mild focal enhancement of the adjacent intracanalicular portion of the optic nerve was also observed.

This gentleman was admitted and treated with amoxicillin and clavulanic acid 500/125 mg orally three times daily, clarithromycin $500 \mathrm{mg}$ orally twice daily, betametasone $0.1 \%$ $\mathrm{w} / \mathrm{v}$ two drops nasally three times daily, fluticasone $110 \mu \mathrm{g}$ nasally daily and saline nasal rinses twice daily.

His condition improved over the following 3 days with the visual acuity from his left eye improving to $6 / 6$. He declined exploratory sinus surgery at this time and was scheduled for 

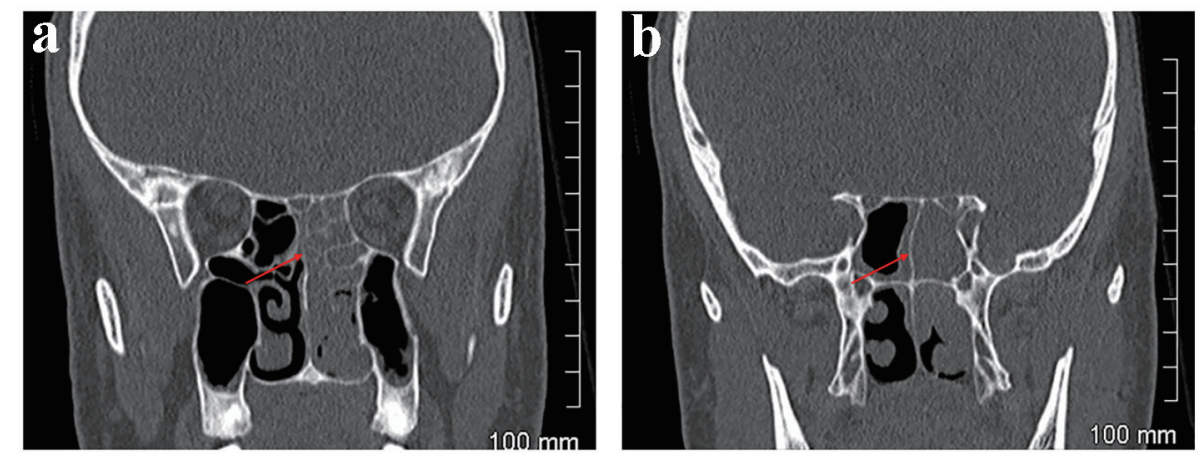

Figure 1. Case 1. CT orbits. Coronal sections. Left ethmoidal sinusitis adjacent to left orbit anteriorly (a) and posteriorly, at the apex of the orbit (b).
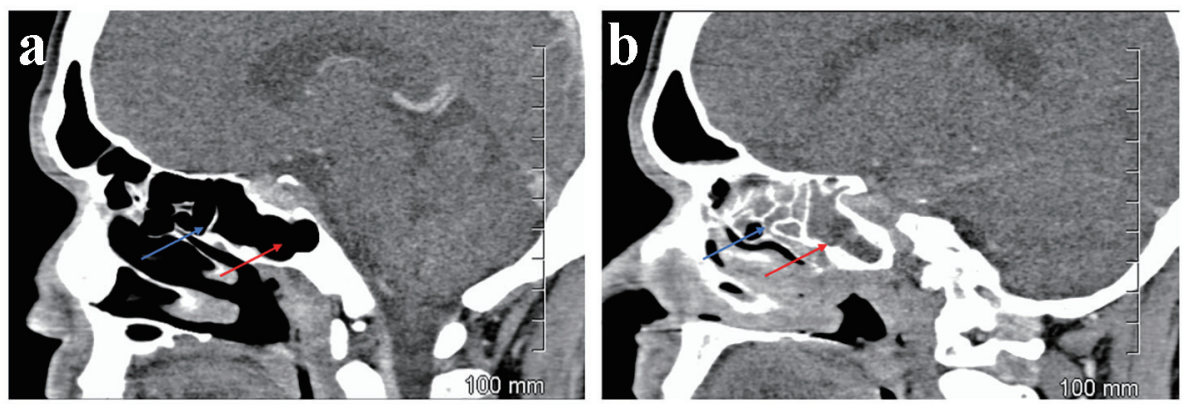

Figure 2. Case 1. CT orbits. Sagittal sections. Aerated ethmoidal (blue arrow) and sphenoidal sinuses (red arrow) on the right (a) but opacified on the left (b).

routine review 3 months later.

\section{Case 2}

A 20-year-old Indian gentleman attended the eye casualty service with 3 months history of blurred vision from his right eye. He described difficulty breathing through his nose. He was lethargic. He felt nauseous and had been vomiting.

He had been congested nasally and had had purulent rhinorrhoea, intermittently, for 15 months. He had also experienced right frontal and parietal headache over this time the severity of which had increased over the month preceding his presentation.
His past medical history was unremarkable with no history of asthma or tuberculosis. He denied atopy or allergy. He was a non-smoker and took no regular medications.

At examination, this gentleman could only perceive light from his right eye. His Snellen visual acuity was $6 / 6$ from his left eye. He had right relative afferent papillary defect. His right optic nerve was gray, the neuroretinal rim almost completely absent. No abnormalities of the left eye were noted. At nasendoscopy polyps were noted.

Laboratory investigations revealed WCC $15.5 \times 10^{9} / \mathrm{L}$ and neutrophils $13.04 \times 10^{9} / \mathrm{L}$, ESR $21 \mathrm{~mm} / \mathrm{h}$ and CRP $81 \mathrm{mg} / \mathrm{L}$.

As can be seen from Figure 3, computed tomography of the orbits and sinuses identified a mass in the paranasal sinuses
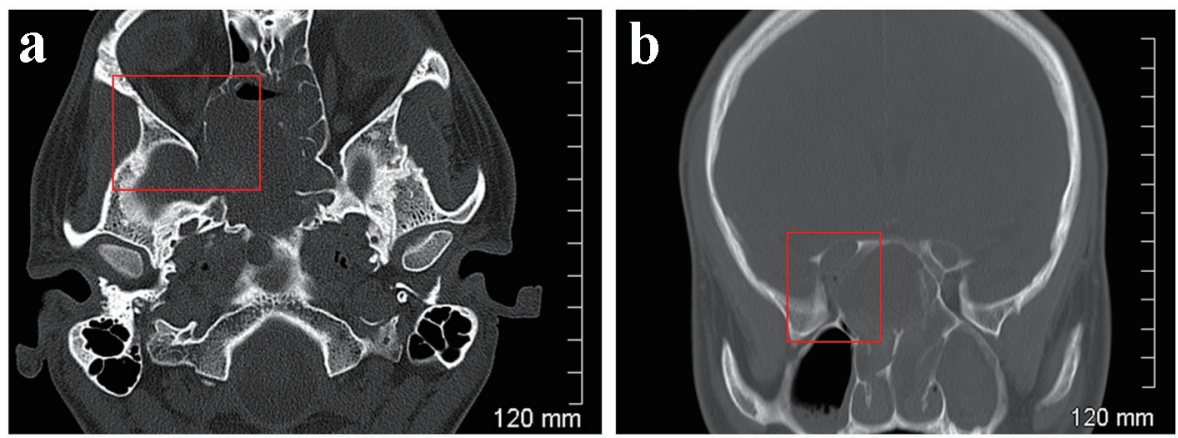

Figure 3. Case 2. CT orbits. Bone windows. Axial section (a) and coronal reformatted section (b). Remodelling and osseous destruction of the right lamina papyracea causing significant stenosis of the right orbital apex. 


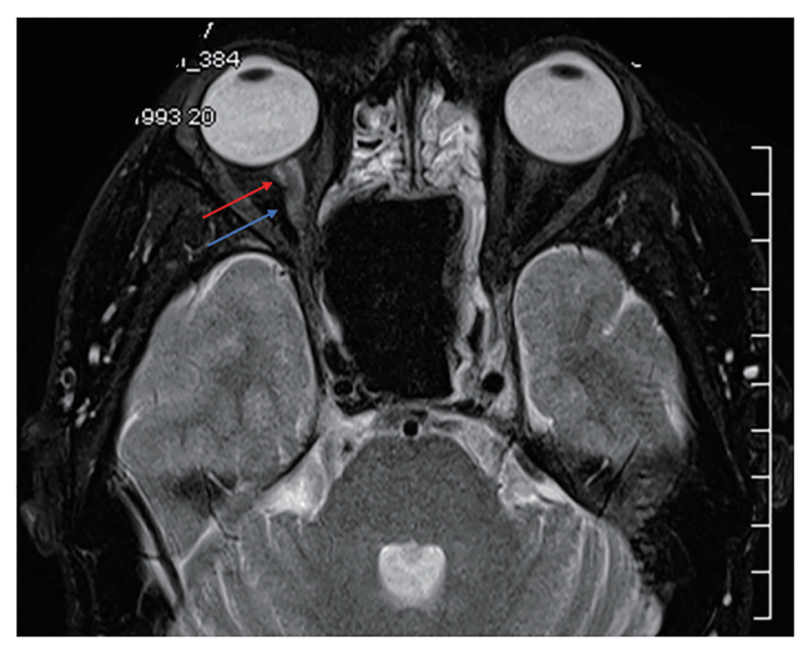

Figure 4. Case 2. MRI orbits. T2 weighted. Axial section. Enlargement of the right optic nerve indicated by the blue arrow. Enhancement around the optic nerve indicated by the red arrow suggests this is due to oedema or the accumulation of fluid within the nerve sheath complex.

on the right causing bony destruction and abutting the right orbital apex and involving the chiasm. As can be seen from Figure 4, magnetic resonance imaging (MRI) demonstrated enlargement of the optic nerve on the right. A chest X-ray revealed no abnormalities.

The patient was admitted and treated with intravenous vancomycin $15 \mathrm{mg} / \mathrm{kg}$ twice daily, cefotaxime $2 \mathrm{~g}$ six times daily, amphotericin B $0.5 \mathrm{mg} / \mathrm{kg}$ daily and metronidazole 7.5 $\mathrm{mg} / \mathrm{kg}$ twice daily.

He underwent emergency functional endoscopic sinus surgery at which extensive sinus disease was noted. The sphenoid sinuses had expanded. The internal carotid arteries were exposed bilaterally. The optic nerve was visible via the wall of the sphenoid sinuses laterally on the right.

Samples obtained at this surgery cultured Aspergillus flavus.

The patient required two further functional endoscopic sinus surgery procedures at 13 and 18 days after his presentation. An examination under anesthesia 2 weeks after the last of these confirmed control of his sinus disease. As can be seen from Figure 5, CT orbits corroborated this. He received oral voriconazole $400 \mathrm{mg}$ twice daily for 12 months on the advice of the infectious diseases team. He did not recover vision from his right eye.

\section{Discussion}

Optic neuritis is an inflammatory neuropathy affecting the optic nerve that presents with visual loss. The patient may also complain of pain with eye movement. An afferent pupillary defect is present and visual field loss may be demonstrated. Optic neuritis secondary to sinus disease is an infrequent but documented association [2]. If unabated, as the second case described here illustrates, optic neuropathy or damage to the optic nerve may result.

There are various means by which sinusitis is postulated to give rise to optic neuritis and/or neuropathy. Direct spread of the sinus infection to the optic nerve is probably the most common way in which this occurs [5]. Osteomyelitis affecting the sinus walls secondary to chronic infection may also be in direct contact with the nerve [6].

Compressive optic neuropathy may be caused by ethmoid and/or sphenoid sinus mucoceles or mucopyoceles and/or associated edema and thickening of the sinus walls [7]. Polyps involving the mucosa of the sphenoid sinus also cause compression of the nerve [4].

The local anatomy of the venous circulation in the orbitalapical region may also play a role in the pathogenesis of optic neuropathy associated with sinus disease. Optic neuropathy could be related to the spread of cytokines and/or immune mediators from the sinuses to the orbital apical portion of the optic nerve through the local venous circulation, or to local vasomotor changes for example. That the area of the most prominent inflammatory changes observed in the optic nerves of those patients with optic neuropathy on a background of sinus disease in previous studies was found where the superior and inferior ophthalmic veins traversed the orbit close to the nerve adds some weight to this theory [8]. Secondary inflammatory occlusive vasculitis causing optic neuritis would explain the rapid resolution which occurs in some cases following antibiotic therapy.

It is also conceivable that a systemic immune response
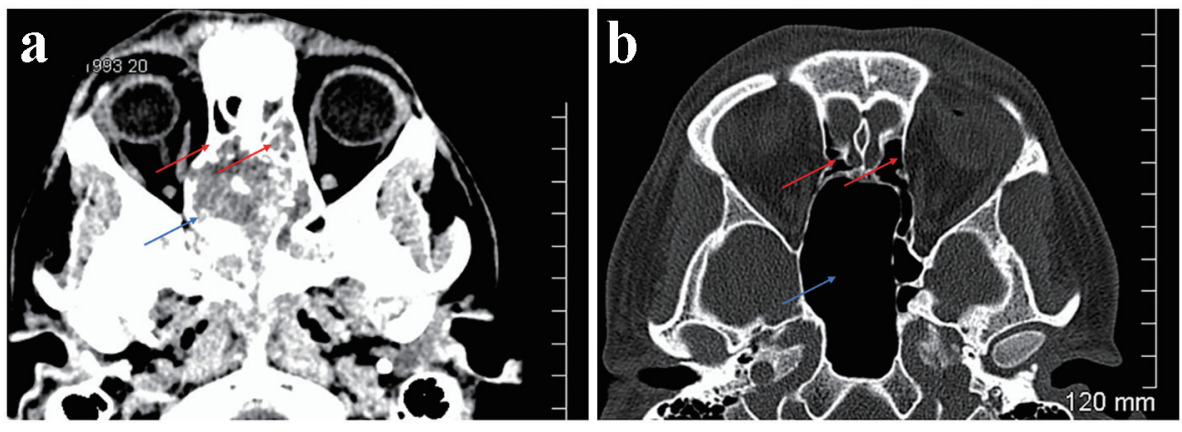

Figure 5. Case 2. CT orbits. Axial sections. Soft tissue window (a). Bone window (b). Extensive soft tissue mass centred on the sphenoid sinuses (blue arrow) but extending to the posterior ethmoidal sinuses (red arrows) (a). Following treatment the sphenoid sinus is greatly enlarged but aerated (blue arrow) as are the ethmoidal sinuses (red arrows) (b). 
initiated by the infectious/inflammatory process in the sinuses could secondarily cause inflammatory changes in the optic nerves by a cross-reacting or non-specific immune mechanism. It is however difficult to envision a systemic mechanism targeting the optic nerves so particularly.

Incidentally noted sphenoid sinus disease is uncommon. An examination of 300 consecutive, routine, neuro-radiological CT scans found sphenoid sinus opacity in only 21 or $7 \%$ cases. The maxillary and ethmoid sinuses were abnormal in $23 \%$ and $34 \%$ cases, respectively. Of those patients with abnormal sphenoid sinuses 5 or $24 \%$ had visual problems associated with the abnormality [9]. When present, therefore, opacity of the sphenoid sinus is likely to be significant.

MRI and CT are invaluable in diagnosing sinusitis and evaluating the patient with associated visual loss. In the second case described here, the CT scan revealed opacification of the sinuses and speeded preparations for surgical decompression of the sinuses. In contrast to the MRI that is the preferred means of investigating "typical" optic neuritis associated with demyelinating disease then, $\mathrm{CT}$ of the orbits and sinuses with 3 $\mathrm{mm}$ coronal sections may be preferred for the investigation of optic neuritis associated with sinusitis because it can be used as an anatomic guide for subsequent endoscopic sinus surgery techniques as necessary [1].

During the normal embryological development of a sinus, pneumatisation may involve adjacent bones. For example, the maxillary sinuses can extend into the zygomatic bones, and the ethmoid air cells can involve the frontal, sphenoid and maxillary bones [10]. An Onodi cell refers to a posterior ethmoidal air cell that has extended into the sphenoid bone [11]. The prevalence of Onodi cells varies from $7 \%$ using CT to $60 \%$ by anatomic dissection using cadavers [12-14].

The recognition of an Onodi cell is important for two reasons [10]. Firstly, as a result of its proximity to the optic nerve, sinus infection of the Onodi cells can result in contiguous infection of the nerve and, in turn, optic neuropathy. Mucocoeles of Onodi cells have also been reported to cause unilateral as well as bilateral visual loss [15-17]. Secondly the risk of optic nerve injury, a devastating complication of endoscopic sinus surgery, is increased [14].

Acute sphenoid sinusitis can be fatal [18]. It may be associated with serious complications including permanent cranial nerve deficits. The incidence of vision loss and third, fourth, fifth and sixth cranial nerve palsies for inflammatory lesions have been reported to be $12 \%$ and $12 \%$, respectively [19].

Visual loss in association with sphenoid sinusitis should be considered a rhinological emergency [6]. Parenteral antimicrobial therapy is recommended as the first-line treatment. The initial presentations of impaired vision and/or afferent pupillary defect associated with ipsilateral sinusitis have been cited as indications for surgical exploration of the involved sinuses [20]. The first case we describe here illustrates that this may not always be necessary. Drainage and sinus decompression should however be performed if the symptoms worsen or continue for $24-48 \mathrm{~h}$ or if there are signs of complications.

Complication rates of endoscopic sinus surgery range from $2 \%$ to $17 \%$ depending on the study reviewed [4]. In experienced hands, the overall complication rate is around $9 \%$ with those most common being adhesion formation, orbital he- matoma and antrostomy closure. More serious complications such as cerebrospinal fluid leak with meningitis, diplopia and blindness are very rare. Overall, endoscopic sphenoethmoidectomy is a safe procedure in experienced hands [21, 22]. Concomitant corticosteroid treatment is often indicated. It should not however be used alone in the treatment of optic neuritis associated with sinusitis as undesirable outcomes may result.

\section{Conclusion}

Though rhinogenic optic neuropathy as a complication of sinusitis is uncommon, this report reaffirms the importance of considering and recognizing sinusitis as a possible cause of visual loss and the need for the prompt initiation of medical and surgical treatment of the underlying disease. The presence of sinus opacity and particularly of the sphenoid and/or ethmoidal sinuses in patients with optic neuritis may well be significant and should not be dismissed as an incidental finding. The first case we describe here adds further evidence to previous reports in the literature that optic neuritis can occur with sinusitis secondary to non-compressive mechanisms. The second case we describe here confirms that chronic sinusitis is an indolent inflammatory process that can cause visual loss.

\section{Learning points}

Radiological imaging of the sinuses should be considered in patients presenting with features suggestive of optic neuritis who are outside the normal age range, have headache and/or systemic features, or who have a history of sinus disease, to exclude pathology involving the sphenoid and/or ethmoid sinuses and in turn the adjacent optic nerve [4].

In the context of visual loss opacity of the sphenoid and/or ethmoid sinuses should not be dismissed as incidental.

Ophthalmologists, otolaryngologists and radiologists should be aware of the potential for sinusitis of the Onodi cell to cause optic neuritis and/or neuropathy [10].

As the first case here illustrates, prompt, appropriate treatment can restore vision in the affected eye. As the second case here illustrates, a delay in appropriate treatment can lead to irreversible visual loss.

In an era where demyelinating diseases such as multiple sclerosis have dominated the diagnosis, investigation and management of optic neuritis, other treatable causes of the same including sinus disease should not be overlooked.

\section{Ethics}

This manuscript was produced in accordance with the terms outlined by the Declaration of Helsinki.

\section{Conflict of Interest}

The authors have no conflict of interest to report. 


\section{Grant Support}

No grant support was received.

\section{References}

1. Kountakis SE, Maillard AA, Stiernberg CM. Optic neuritis secondary to sphenoethmoiditis: surgical treatment. Am J Otolaryngol. 1995;16(6):422-427.

2. Rothstein J, Maisel RH, Berlinger NT, Wirtschafter JD. Relationship of optic neuritis to disease of the paranasal sinuses. Laryngoscope. 1984;94(11 Pt 1):1501-1508.

3. Awerbuch G, Labadie EL, Van Dalen JT. Reversible optic neuritis secondary to paranasal sinusitis. Eur Neurol. 1989;29(4):189-193.

4. Moorman CM, Anslow P, Elston JS. Is sphenoid sinus opacity significant in patients with optic neuritis? Eye (Lond). 1999;13(Pt 1):76-82.

5. Teed RW. Meningitis from the sphenoid sinus. Arch Otolaryngol. 1938;28:589-619.

6. Dale BA, Mackenzie IJ. The complications of sphenoid sinusitis. J Laryngol Otol. 1983;97(7):661-670.

7. Newton N, Jr., Baratham G, Sinniah R, Lim A. Bilateral compressive optic neuropathy secondary to bilateral sphenoethmoidal mucoceles. Ophthalmologica. 1989;198(1):13-19.

8. Slavin ML, Glaser JS. Acute severe irreversible visual loss with sphenoethmoiditis-'posterior' orbital cellulitis. Arch Ophthalmol. 1987;105(3):345-348.

9. Digre KB, Maxner CE, Crawford S, Yuh WT. Significance of $\mathrm{CT}$ and MR findings in sphenoid sinus disease. AJNR Am J Neuroradiol. 1989;10(3):603-606.

10. Lim SA, Sitoh YY, Lim TC, Lee JC. Clinics in diagnostic imaging (120). Right rhinogenic optic neuritis secondary to mucocoele of the Onodi cell. Singapore Med J.
2008;49(1):84-87; quiz 88.

11. Lang J. Clinical anatomy of the nose, nasal cavity and paranasal sinuses. New York, NY: Georg Thieme Verlag. 1989:88-89.

12. Thanaviratananich S, Chaisiwamongkol K, Kraitrakul S, Tangsawad W. The prevalence of an Onodi cell in adult Thai cadavers. Ear Nose Throat J. 2003;82(3):200-204.

13. Driben JS, Bolger WE, Robles HA, Cable B, Zinreich SJ. The reliability of computerized tomographic detection of the Onodi (Sphenoethmoid) cell. Am J Rhinol. 1998;12(2):105-111.

14. Unal B, Bademci G, Bilgili YK, Batay F, Avci E. Risky anatomic variations of sphenoid sinus for surgery. Surg Radiol Anat. 2006;28(2):195-201.

15. Klink T, Pahnke J, Hoppe F, Lieb W. Acute visual loss by an Onodi cell. Br J Ophthalmol. 2000;84(7):801-802.

16. Yoshida K, Wataya T, Yamagata S. Mucocele in an Onodi cell responsible for acute optic neuropathy. Br J Neurosurg. 2005;19(1):55-56.

17. Kitagawa K, Hayasaka S, Shimizu K, Nagaki Y. Optic neuropathy produced by a compressed mucocele in an Onodi cell. Am J Ophthalmol. 2003;135(2):253-254.

18. Lee LA, Huang CC, Lee TJ. Prolonged visual disturbance secondary to isolated sphenoid sinus disease. Laryngoscope. 2004;114(6):986-990.

19. Lawson W, Reino AJ. Isolated sphenoid sinus disease: an analysis of 132 cases. Laryngoscope. 1997;107(12 Pt 1):1590-1595.

20. Patt BS, Manning SC. Blindness resulting from orbital complications of sinusitis. Otolaryngol Head Neck Surg. 1991;104(6):789-795.

21. Stankiewicz JA. Complications of endoscopic intranasal ethmoidectomy. Laryngoscope. 1987;97(11):1270-1273.

22. Stankiewicz JA. Complications in endoscopic intranasal ethmoidectomy: an update. Laryngoscope. 1989;99(7 Pt 1):686-690. 